\title{
Computational molecular characterization of the flavonoid rutin
}

\author{
Sergio A Payán-Gómez¹,2, Norma Flores-Holguín'1, Antonino Pérez-Hernández¹, Manuel Piñón-Miramontes³ and \\ Daniel Glossman-Mitnik*1
}

\begin{abstract}
In this work, we make use of a model chemistry within Density Functional Theory (DFT) recently presented, which is called M05-2X, to calculate the molecular structure of the flavonoid Rutin, as well as to predict the infrared (IR) and ultraviolet (UV-Vis) spectra, the dipole moment and polarizability, the free energy of solvation in different solvents as an indication of solubility, the HOMO and LUMO orbitals, and the chemical reactivity parameters that arise from Conceptual DFT. The calculated values are compared with the available experimental data for this molecule as a means of validation of the used model chemistry.
\end{abstract}

\section{Background}

Flavonoids are phenolic substances characterized for a low molecular weight and they are abundant in plant tissues, apple being one of the most important (particularly its skin) $[1,2]$. In the human body they show a lot of biological properties as antioxidants, antiallergenic, antibacterial, antifungal, antiviral and anticarcinogenic agents. These characteristics confer to them pharmacological properties useful for the treatment of diseases that go from allergies, bacterial and viral infectious processes, to those of greater risk like the coronary diseases, cancer and HIV [3-5]. The mechanism by which flavonoids carry out their properties, mainly their antioxidant power, is either by inhibiting the formation or activity of reactive oxygen species, or by direct interaction with DNA, enzymes and membrane receptors.

Theoretical investigations of the physical and chemical properties of flavonoids are very important in order to disclose the relationship between the structure, properties and performance, and to help in the design and synthesis of new derivatives with improved properties. We have experimentally found that some natural flavonoids have a strong ability for complexing metal ions, in particular, those related to heavy metals [6-8]. Thus, natural flavonoids could be useful in water treatment, cleaning and

* Correspondence: daniel.glossman@cimav.edu.mx

1 Departamento de Simulación Computacional y Modelado Molecular, CIMAV, SC, Miguel de Cervantes 120, Complejo Industrial Chihuahua, Chihuahua, Chih. 31109, México

Full list of author information is available at the end of the article purification. The objective of this letter is to report the results of the calculation of the molecular structure and properties of the flavonoid Rutin using a recently developed density functional [9]. The IR and UV-Vis spectra, the dipole moment and polarizability, the free energy of solvation in different solvents as an indication of solubility, the HOMO and LUMO orbitals, and the chemical reactivity parameters that arise from Conceptual DFT $[10,11]$ are reported. The calculated values are compared with the available experimental data for this molecule as a means of validation of the used model chemistry. The spectra and the calculated values are important in the sense that they are an indication of the chemical stability, the thermochemistry, the color and the region of the solar spectrum where the absorption takes place, the solubility and the chemical reactivity which is useful to predict the possible complexation sites.

\section{Theory and Computational Details}

For all the calculations, we have chosen the hybrid metaGGA M05-2X functional [9], which consistently provides satisfactory results for several structural and thermodynamic properties. Although there are a new class of functionals, the so called M06 functionals, our own experience indicates that the improvement in the calculated molecular structure and properties of systems of the size that we are considering in this paper is only marginal. The 3-21G(d) basis set was used for the geometry optimizations and evaluations of harmonic frequencies both in

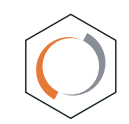

(C) 2010 Glossman-Mitnik et al 
the gas phase and in aqueous solution of the flavonoid. It has been found that this basis set has a remarkable ability to predict the molecular structure and properties of large systems when coupled withe B3LYP density functional [12], and the same has been our own experience when the M05-2X functional is considered. The equilibrium geometry of the studied molecule was determined by means of the gradient technique. The force constants and vibrational frequencies were determined from calculation using the FREQ keyword on the stationary points obtained after the optimization to check if they were true minima. The electronic properties were calculated with the $6-31+G(d)$ basis set. A suitable description of this basis set is provided in some of the most important Computational Chemistry recent books [13-16]. Solvation energies were computed by the Integral Equation Formalism - Polarizable Continuum Model (IEF-PCM) [17], including the UAHF model. All the calculations have been performed with the Gaussian 03W series of programs [18].

The calculation of the ultraviolet (UV-Vis) spectra of the flavonoid and their metallic complexes has been performed by solving the time dependent Kohn-Sham equations according to the method implemented in Gaussian 03W [13,19-21]. The equations have been solved for 10 excited states.

The infrared (IR) and ultraviolet (UV-Vis) spectra were calculated and visualized using the Swizard program [22]. In all cases the displayed spectra show the calculated frequencies and absorption wavelengths. The vertical ionization potential I and electron affinity A were calculated in two ways: i) as the difference between the total energy of the neutral molecule and the corresponding ions, taken at the geometry of the neutral molecule in order to keep the external potential constant, and ii) considering the approximation given by the Koopmans' theorem [1316], where the HOMO energy is equal to $-\mathrm{I}$ and the LUMO energy is equal to -A.

The HOMO and LUMO molecular orbitals were visualized with the ChemCraft 1.6 [23] program, while the condensed Fukui functions were calculated with the aid of the AOMix software [24].

\section{Results and Discussion}

The results for the equilibrium conformation of the neutral molecule of 2-(3,4-dihydroxyphenyl)-5,7-dihydroxy$3-[(2 S, 3 R, 4$ S,5S,6R)-3,4,5-trihydroxy-6([(2R,3R,4R,5R,6S)-3,4,5-trihydroxy-6-methyloxan-2-

yl]oxymethyl) oxan-2 yl]oxy-4H-chromen-4-one (or rutin, for short) calculated with the M05-2X/3-21G(d) model chemistry are presented in Figure 1 through a representation of the molecular structure showing the atomic labeling and numbering as well as the interatomic bond lengths and several selected angles. The results have been compared with those of the quercetin molecule $[25,26]$. As the comparison of the computed molecular structure of quercetin with the X-ray results has been presented already $[25,26]$, we are not repeating it here. However, it can be said that the agreement between the computed quercetin moiety of rutin and the quercetin Xray results is very good. It should be remarked that there are two H-bonds belonging to $\mathrm{O} 30$ with $\mathrm{H} 29$, and $\mathrm{O} 68$ with H31. This could be an explanation of the increased water, methanol and ethanol solubility (see below).

The infrared spectrum (IR) for the rutin molecule calculated with the M05-2X/3-21G(d) model chemistry is displayed in Figure 2. The vibrational band assignments have been done using the ChemCraft for Windows molecular visualization program. By comparison with the experimental IR spectrum [27], an average scaling factor of 0.995 could be estimated. In Table 1, we present a comparison of the experimental, computed and scaled frequencies for the rutin molecule as an assessment of the M05-2X functional for calculating vibrational frequencies. However, it must be noted that a strong peak at 2747 $\mathrm{cm}^{-1}$ related to an internal $\mathrm{H}$-bond has been omitted in order not to obscure the rest of the spectrum and for the sake of clarity. Thus, it is expected that the model chemistry used in this work can reproduce the experimental spectrum of the rutin molecule with a certain degree of accuracy.

The ultraviolet spectrum (UV-Vis) of the rutin molecule was calculated with TDDFT using the M05-2X/6$31+\mathrm{G}(\mathrm{d}, \mathrm{p})$ model chemistry. The results in Table 2 show the first ten electronic transitions states of rutin, both in nanometers $(\mathrm{nm})$ and electron-volts $(\mathrm{eV})$, the oscillators strengths (f) that can give an idea of the intensity of the transition, and the orbital assignments, indicating the percentage of any $\mathrm{H}-\mathrm{n} \mathrm{T} \mathrm{L}+\mathrm{n}$ transition involved. The wavelength belonging to the HOMO-LUMO transition will take place at $290 \mathrm{~nm}$. As the HOMO-LUMO transition takes place in the ultraviolet region, close to but out of the visible zone, it can be predicted that this molecule will be colorless or slightly colored.

The molecular dipole moment is perhaps the simplest experimental measure of charge distribution in a molecule. The accuracy of the overall distribution of electrons in a molecule is hard to quantify, since it involves all the multipoles. The polarizability $a$ contributes to the understanding of the response of the system when the external field is changed, while the number of electrons $\mathrm{N}$ is kept fixed. The polarizability is calculated as the average of the polarizability tensor $\langle\alpha\rangle=\frac{1}{3}\left(\alpha_{x x}+\alpha_{y y}+\alpha_{z z}\right)$. From 

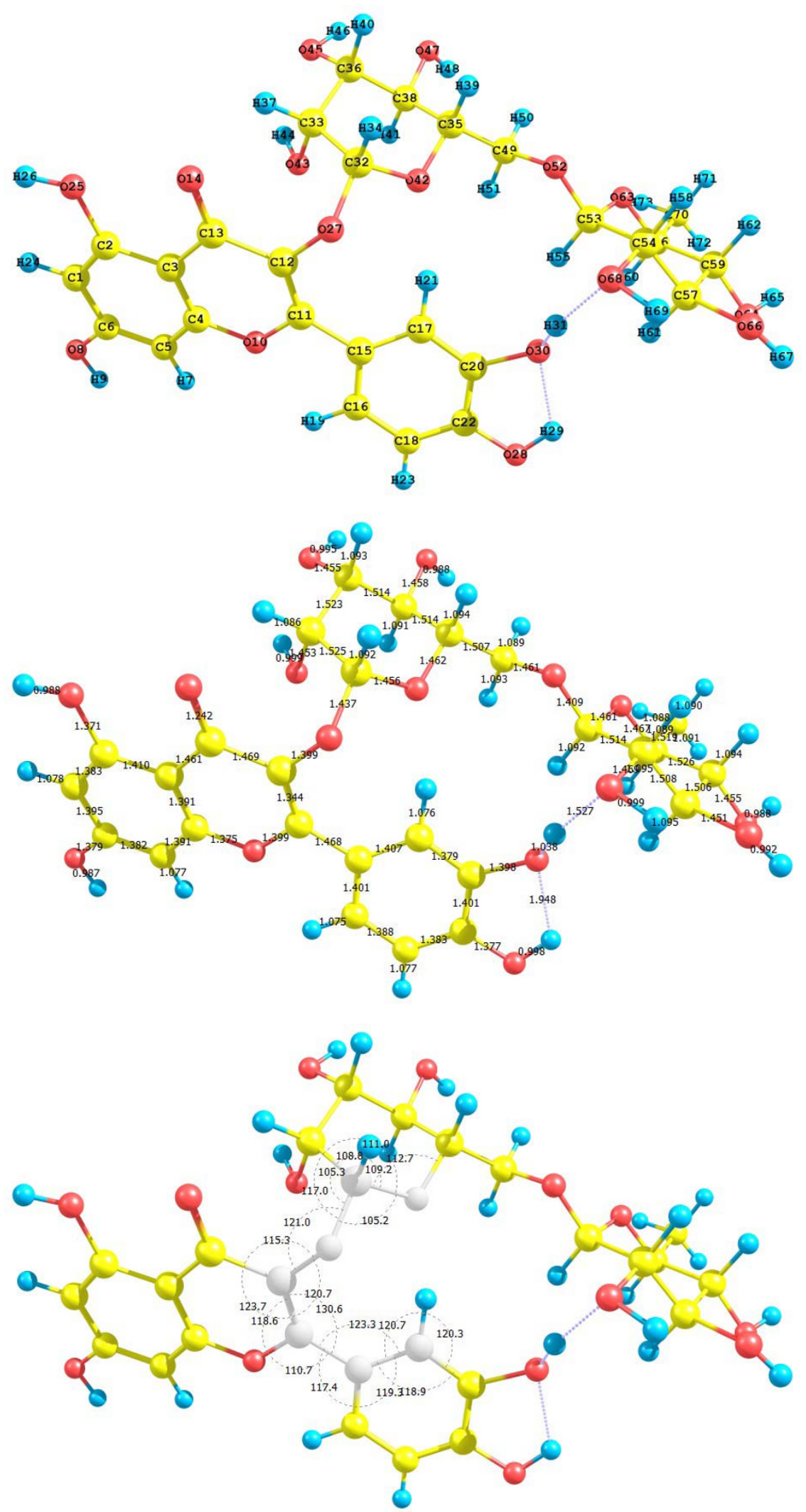

Figure 1 Atomic labeling, interatomic bond distances ( $(\AA)$ and selected bond angles (deg) for the rutin molecule. 
Table 1: Experimental, computed and scaled frequencies $\left(\mathrm{cm}^{-1}\right)$ for the rutin molecule calculated at the $M 05-2 X / 3-21 \mathrm{G}(\mathrm{d})$ level of theory

\begin{tabular}{lllllllll}
\hline Exp & Computed & Scaled & Exp & Computed & Scaled & Exp & Computed & Scaled \\
\hline 598 & 541 & 538 & 919 & 909 & 904 & 1234 & 1235 & 1229 \\
634 & 606 & 603 & 924 & 925 & 920 & 1285 & 1288 & 1282 \\
657 & 659 & 656 & 944 & 942 & 937 & 1360 & 1361 & 1354 \\
713 & 707 & 703 & 977 & 975 & 967 & 1466 & 1464 & 1457 \\
719 & 713 & 709 & 1012 & 1031 & 1026 & 1493 & 1485 & 1478 \\
724 & 720 & 716 & 1065 & 1081 & 1076 & 1605 & 1607 & 1599 \\
729 & 743 & 739 & 1091 & 1094 & 1089 & 1656 & 1670 & 1662 \\
791 & 783 & 779 & 1115 & 1127 & 1131 & 2920 & 2748 & 2734 \\
805 & 824 & 820 & 1121 & 1140 & 1134 & 2959 & 3079 & 3064 \\
834 & 830 & 826 & 1133 & 1158 & 1152 & 2984 & 3157 & 3141 \\
878 & 869 & 865 & 1152 & 1176 & 1170 & 3418 & 3434 & 3417 \\
\end{tabular}

the present calculations, the total energy, the total dipole moment and the isotropic polarizability of the ground state with the $6-31+\mathrm{G}(\mathrm{d}, \mathrm{p})$ model chemistry are 2250.341 au, 7.6877 Debye and 177.57 Bohr $^{3}$ for the rutin molecule. These results for the dipole moment and the isotropic polarizability could be of interest as an indication of the solubility and chemical reactivity of the studied molecule, not only for it synthesis but for the

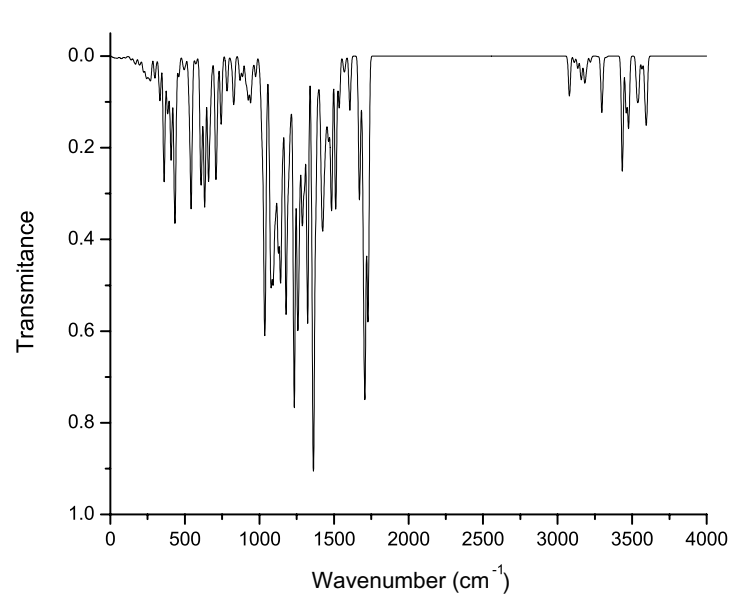

Figure 2 Infrared spectrum (IR) of the rutin molecule computed with the M05-2X/3-21G(d) model chemistry (A strong peak at $2747 \mathrm{~cm}^{-1}$ related to an internal $\mathrm{H}$-bond has been omitted for the sake of clarity) potential application in complexation of metal cations for water cleaning and purification.

The free energy of solvation $\Delta G$ (solv) of the molecule have been calculated for rutin by resorting to the M05$2 \mathrm{X} / 6-31+\mathrm{G}(\mathrm{d}, \mathrm{p})$ model chemistry coupled with the Integral-Equation-Formalism of the Polarized Continuum Model (IEF-PCM) for different solvents as implemented in Gaussian 03. The solubility of a molecule will depend on several kinetic and thermodynamic factors. However, it can be said that the magnitude and the sign of $\Delta G($ solv) could be a good approximation as an index of solubility. In this way, a negative sign and a large magnitude will be an indication of increased solubility. The results of these calculations for the studied molecule can be summarized as follows: Acetone $=-18.36 \mathrm{Kcal} / \mathrm{mol}$, Acetonitrile = $6.05 \mathrm{Kcal} / \mathrm{mol}$, Aniline $=11.36 \mathrm{Kcal} / \mathrm{mol}$, Benzene $=0.10$ $\mathrm{Kcal} / \mathrm{mol}, \mathrm{CCl} 4=-0.14 \mathrm{Kcal} / \mathrm{mol}$, Chlorobenzene $=-5.42$ $\mathrm{Kcal} / \mathrm{mol}$, Chloroform $=-9.03 \mathrm{Kcal} / \mathrm{mol}$, Cyclohexane = $6.32 \mathrm{kcal} / \mathrm{mol}$, Dichloroethane $=-13.37 \mathrm{Kcal} / \mathrm{mol}$, Dichloromethane $=-15.59 \mathrm{Kcal} / \mathrm{mol}$, Diethylether $=-13.74 \mathrm{Kcal} /$ $\mathrm{mol}, \mathrm{DMSO}=-15.05 \mathrm{Kcal} / \mathrm{mol}$, Ethanol $=-52.88 \mathrm{Kcal} /$ mol, Heptane $=-7.73 \mathrm{Kcal} / \mathrm{mol}$, Methanol $=-56.35 \mathrm{Kcal} /$ $\mathrm{mol}$, Nitromethane $=-14.48 \mathrm{Kcal} / \mathrm{mol}$, THF $=-10.58$ $\mathrm{Kcal} / \mathrm{mol}$, Toluene $=-2.36 \mathrm{Kcal} / \mathrm{mol}$, and Water $=-49.42$ $\mathrm{Kcal} / \mathrm{mol}$. These values could be an indication that the studied molecule will be mostly soluble in ethanol, methanol, and water, and this can be related to the results obtained for the dipole moment and polarizability.

The HOMO and LUMO of rutin calculated with the M05-2X/6-31+G(d,p) model chemistry are displayed in Figure 3. The HOMO and LUMO densities are over the flavonoid moiety, but not over the glycoside rest. This can 
Table 2: Electronic transition states of rutin ( $\mathrm{nm}, \mathrm{eV}$, oscillator strengths ( $\mathrm{f}$ ), and transition assignments as calculated with TD-DFT and the M05-2X/6-31+G(d,p) level of theory

\begin{tabular}{|c|c|c|c|c|}
\hline Number & nm & $\mathrm{eV}$ & (f) & Assignment; H = HOMO, L = LUMO \\
\hline 1 & 319.3 & 3.88 & 0.0057 & $\mathrm{SH}-4 \mathrm{~T} \mathrm{~L}+0(+69 \%)$ \\
\hline 2 & 290.0 & 4.28 & 0.5920 & $\mathrm{SH}-0 \mathrm{~T} \mathrm{~L}+0(+81 \%)$ \\
\hline \multirow[t]{2}{*}{3} & 256.3 & 4.84 & 0.0065 & S H-1 T L+0(+59\%) H-0 T L+1(14\%) \\
\hline & & & & $\mathrm{H}-2 \mathrm{~T} L+1(6 \%) \mathrm{H}-3 \mathrm{~T} \mathrm{~L}+6(+5 \%)$ \\
\hline \multirow[t]{3}{*}{4} & 247.4 & 5.01 & 0.0043 & S H-3 T L+O(+31\%) H-2 T L+0(+17\%) \\
\hline & & & & $\mathrm{H}-1 \mathrm{~T} L+1(15 \%) \mathrm{H}-0 \mathrm{~T} \mathrm{~L}+9(14 \%)$ \\
\hline & & & & $\mathrm{H}-0 \mathrm{~T} \mathrm{~L}+7(+9 \%)$ \\
\hline \multirow[t]{2}{*}{5} & 235.3 & 5.27 & 0.0679 & S H-2 T L+0(+43\%) H-3 T L+0(23\%) \\
\hline & & & & $\mathrm{H}-1 \mathrm{~T} \mathrm{~L}+0(+7 \%)$ \\
\hline \multirow[t]{3}{*}{6} & 228.4 & 5.43 & 0.1671 & S H-0 T L+1(+37\%) H-1 T L+0(+15\%) \\
\hline & & & & $\mathrm{H}-1 \mathrm{~T} L+1(+9 \%) \mathrm{H}-2 \mathrm{~T} \mathrm{~L}+0(8 \%)$ \\
\hline & & & & $\mathrm{H}-3 \mathrm{~T} \mathrm{~L}+0(+8 \%)$ \\
\hline \multirow[t]{3}{*}{7} & 219.7 & 5.64 & 0.0289 & S H-0 T L+1(+26\%) H-2 T L+1(17\%) \\
\hline & & & & $\mathrm{H}-5 \mathrm{~T}$ L+0(+13\%) H-1 T L+1(7\%) \\
\hline & & & & $\mathrm{H}-3 \mathrm{~T} \mathrm{~L}+6(+5 \%)$ \\
\hline \multirow[t]{2}{*}{8} & 213.3 & 5.81 & 0.0236 & $\mathrm{SH}-0 \mathrm{~T} \mathrm{~L}+5(+42 \%) \mathrm{H}-0 \mathrm{~T} \mathrm{~L}+2(9 \%)$ \\
\hline & & & & $\mathrm{H}-0 \mathrm{~T} \mathrm{~L}+6(+6 \%) \mathrm{H}-0 \mathrm{~T} \mathrm{~L}+7(+5 \%)$ \\
\hline \multirow[t]{3}{*}{9} & 212.7 & 5.83 & 0.5713 & S H-3 T L+0(+20\%) H-0 T L+7(14\%) \\
\hline & & & & $\mathrm{H}-0 \mathrm{~T} \mathrm{~L}+9(+13 \%) \mathrm{H}-2 \mathrm{~T} \mathrm{~L}+0(+9 \%)$ \\
\hline & & & & $\mathrm{H}-1 \mathrm{~T} \mathrm{~L}+1(+8 \%)$ \\
\hline \multirow[t]{3}{*}{10} & 206.3 & 6.01 & 0.0618 & $\mathrm{~S} \mathrm{H}-0 \mathrm{~T} L+6(+32 \%) \mathrm{H}-1 \mathrm{~T} \mathrm{~L}+6(+12 \%)$ \\
\hline & & & & $\mathrm{H}-2 \mathrm{~T}$ L+0(9\%) H-3 T L+1(+7\%) \\
\hline & & & & $\mathrm{H}-2 \mathrm{~T} \mathrm{~L}+1(7 \%) \mathrm{H}-0 \mathrm{~T} \mathrm{~L}+5(7 \%)$ \\
\hline
\end{tabular}

give us an idea of the reactivity of the molecule and means that only the flavonoid moiety will be reactive, for example, in complexation with metal cations.

Within the conceptual framework of DFT [10], the chemical potential $\mu$, which measures the escaping tendency of an electron from equilibrium is defined as:

$$
\mu=\left(\frac{\partial E}{\partial N}\right)_{v(r)}=-\chi
$$

where $X$ is the electronegativity.

The global hardness $\eta$ can be seen as the resistance to charge transfer:

$$
\eta=\frac{1}{2}\left(\frac{\partial^{2} E}{\partial N^{2}}\right)_{v(r)}
$$

Using a finite difference approximation and Koopmans' theorem [13-16], the above expressions can be written as:

$$
\begin{aligned}
& \mu \approx-\frac{1}{2}(I+A) \approx \frac{1}{2}\left(\epsilon_{L}+\epsilon_{H}\right) \\
& \eta \approx \frac{1}{2}(I-A) \approx \frac{1}{2}\left(\epsilon_{L}-\epsilon_{H}\right)
\end{aligned}
$$

where $?_{H}$ and $?_{L}$ are the energies of the highest occupied and the lowest unoccupied molecular orbitals, HOMO and LUMO, respectively.

The electrophilicity index $\omega$ represents the stabilization energy of the system when it gets saturated by electrons coming from the surrounding:

$$
\omega=\frac{\mu^{2}}{2 \eta} \approx \frac{(I+A)^{2}}{2(I+A)} \approx \frac{\left(\in_{L}+\in_{H}\right)^{2}}{2\left(\in_{L}+\epsilon_{H}\right)}
$$

The validity of the Koopmans' theorem within the DFT approximation is controversial. However, it has been shown [28] that although the KS orbitals may differ in shape and energy from the HF orbitals, the combination 


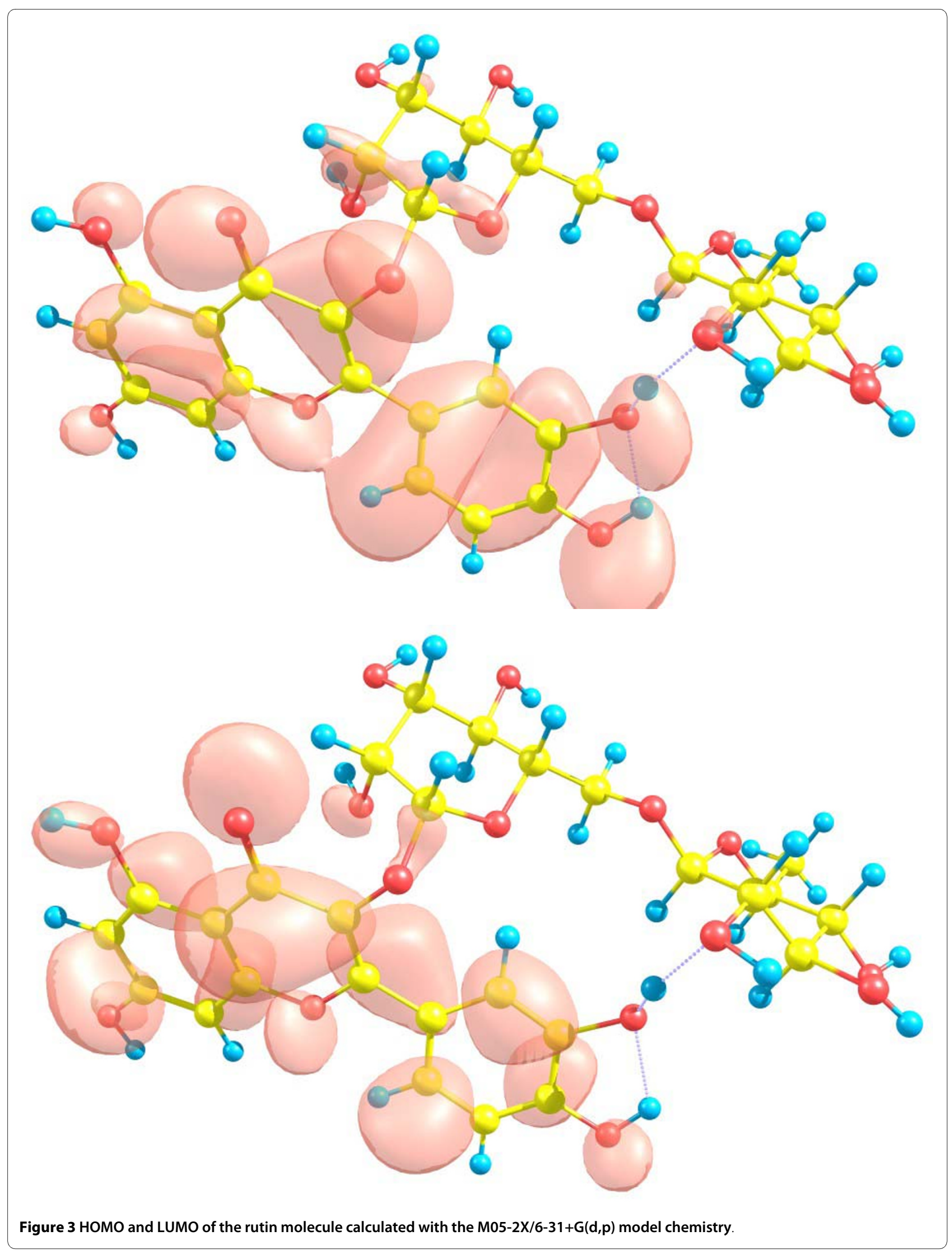


of them produces Conceptual DFT reactivity descriptors that correlate quite well with the reactivity descriptors obtained through Hartree-Fock calculations. Thus, it is worth to calculate the electronegativity, global hardness and global electrophilicity for the rutin molecule using both approximations in order to verify the quality of the procedures.

The results for the vertical I and A of the rutin molecule obtained through energy differences between the ionized and the neutral state, calculated at the geometry of the neutral molecule are $\mathrm{I}=7.284 \mathrm{eV}$ and $\mathrm{A}=0.067 \mathrm{eV}$. The $\mathrm{HOMO}$ and LUMO energies are $-6.836 \mathrm{eV}$ and $-0.522 \mathrm{eV}$, respectively. It can be seen that there is a good qualitative agreement between both results for I, but not for A. The calculated values of the electronegativity, global hardness and global electrophilicity using the I and A are $X=3.676$ $\mathrm{eV},=3.608 \mathrm{eV}$, and $\omega=1.873 \mathrm{eV}$. Using the $\mathrm{HOMO}$ and LUMO energies, within the Koopmans' theorem, the corresponding values are $X=3.679 \mathrm{eV}, \eta=3.158 \mathrm{eV}$, and $\omega=$ $2.143 \mathrm{eV}$. Again, there is a good qualitative agreement for the reactivity parameters calculated through both procedures. It can be concluded that for the particular case of the rutin molecule, the M05-2X/6-31+G(d,p) model chemistry is able to predict the Conceptual DFT reactivity indices calculated through HOMO and LUMO energies as well as from the I and A obtained through energy differences with qualitative similar good accuracy.

The condensed Fukui functions can also be employed to determine the reactivity of each atom in the molecule. The corresponding condensed functions are given by $f_{k}^{+}=q_{k}(N+1)-q_{k}(N) \quad$ (for nucleophilic attack), $f_{k}^{-}=q k(N)-q k(N-1)$ (for electrophilic attack), and $f_{k}^{0}=[q k(N+1)-q k(N-1)] / 2$ (for radical attack), where $q k$ is the gross charge of atom $k$ in the molecule.

It is possible to evaluate condensed Fukui functions from single-points calculations directly, without resorting to additional calculations involving the systems with $\mathrm{N}-1$ and $\mathrm{N}+1$ electrons:

$$
f_{k}^{+}=\sum_{a \in k}\left[c_{a i}{ }^{2}+c_{a i} \sum_{b \neq a} c_{b i} S_{a b}\right] \quad(\text { where } \mathrm{i}=\mathrm{LUMO})
$$

and

$$
f_{k}^{-}=\sum_{a \in k}\left[c_{a i}^{2}+c_{a i} \sum_{b \neq a} c_{b i} S_{a b}\right] \quad(\text { where } \mathrm{i}=\mathrm{HOMO})
$$

with $\mathrm{c}_{a i}$ being the LCAO coefficients and $\mathrm{S}_{a b}$ the overlap matrix. The condensed Fukui functions are normalized, thus $\sum_{k} f_{k}=1$ and $f_{k}^{0}=\left[f_{k}^{+}+f_{k}^{-}\right] / 2$.

The results from the calculation of the condensed Fukui functions for nucleophilic, electrophilic and radical attack have been obtained by resorting to the AOMix molecular analysis program [24]. The sites for electrophilic attack will be those atoms bearing a negative charge and where the Fukui function $f_{k}^{-}$is a maximum. These values confirm that the sites for the electrophilic attack are the $\mathrm{C} 12$ and $\mathrm{C} 22$ atoms. The site for potential nucleophilic attack would depend on the values of $f_{k}^{+}$on the atoms with a positive charge density. The results indicate that the site for nucleophilic attack will be the C11 and $\mathrm{C} 13$ atoms. Finally, the site for radical attack, governed by the values of $f_{k}^{0}$ will be the $\mathrm{C} 12$ atom. The glycoside rings are not very reactive in this context.

\section{Conclusions}

In this work, the M05-2X/3-21G(d) and M05-2X/6$31+G(d, p)$ model chemistries have been applied to the study of a molecule which is potentially useful for water cleaning and purification. The molecular structure for the rutin molecule has been determined by using the M052X/3-21G(d) model chemistry. A comparison has been made with the results from the experimental X-ray crystallography for the flavonoid quercetin. The agreement is generally good. Two internal $\mathrm{H}$-bonds have been described that could be an explanation for the increased solubility of rutin in water, ethanol and methanol.

The shape of the frontier orbitals of this molecule were displayed as well as some electronic parameters like the total energy, the dipole moment and the polarizability and the infrared (IR) and ultraviolet (UV-Vis) spectra for the rutin molecule have been predicted according to the M05-2X/6-31+G(d,p) model chemistry, and an assignment of the principal peaks has been achieved.

The free energy of solvation $\Delta \mathrm{G}$ (solv) of the rutin molecule has been calculated by resorting to the M05-2X/6$31+\mathrm{G}(\mathrm{d}, \mathrm{p})$ model chemistry coupled with the IntegralEquation-Formalism of the Polarized Continuum Model (IEF-PCM) for different solvents and the results gave an indication of water, ethanol and methanol as the solvents in which this molecule could be potentially soluble. 
The ionization potential I and the electron affinity A have been calculated through energy differences between the ionic and the neutral states, all at the geometry of the neutral molecule, and they have been compared well with the results obtained from the HOMO and LUMO energies obtained through the Koopmans' theorem procedure. The results indicate a qualitative good agreement, which can be consider an indication of the goodness of the proposed model chemistry.

The M05-2X density functional in combination with several basis sets appears to be a useful tool for the study of the molecular structure and electronic properties of flavonoids and the possible nanostructures derived from them, and further applications to several molecular systems of this kind are being pursued in our laboratory.

\section{Competing interests}

The authors declare that they have no competing interests.

\section{Authors' contributions}

SAPG carried out the DFT calculations and wrote some portions of the paper. $\mathrm{NFH}$ analysed the IR and UV-Vis spectra. APH and DGM conceived of the study, analysed all the data, discussed the results and wrote the manuscript. MPM discussed the results and revised the manuscript. All authors read and approved the final manuscript.

\section{Acknowledgements}

This work has been partially supported by Consejo Nacional de Ciencia y Tecnología (CONACYT, Mexico) and by Fondo Mixto del Estado de Baja California (FOMIX-BC) through Project 69363. SAPG gratefully acknowledges a fellowship from CONACYT. NFH, APH and DGM are researchers of CONACYT and CIMAV.

\section{Author Details}

1Departamento de Simulación Computacional y Modelado Molecular, CIMAV SC, Miguel de Cervantes 120, Complejo Industrial Chihuahua, Chihuahua, Chih. 31109, México, 2Facultad de Ingeniería, Universidad Autónoma de Chihuahua, Nuevo Campus Universitario, Chihuahua, Chih. 31125, México and 3 Junta Municipal de Aguas y Saneamiento de Chihuahua, Perif. Ortiz Mena y Av. Politécnico S/N, Colonia Quintas del Sol, Chihuahua, Chih. 31350, México

Received: 18 March 2010 Accepted: 22 June 2010

Published: 22 June 2010

\section{References}

1. Pietta PG: Flavonoids as antioxidants. J Nat Prod 2000, 63:1025-1042.

2. Wolfe K, Wu X, Liu RH: Antioxidant activity of apple peels. J Agric Food Chem 2003, 51:609-614.

3. Scalbert A, Williamson G: Dietary intake and bioavailability of polyphenols. J Nutr 2000, 130:2073S-2085S.

4. Erkoc S, Erkoc F, Keskin N: Theoretical investigation of quercetin and its radical isomers. J Mol Struct - THEOCHEM 2003, 631:141-146.

5. Russo N, Toscano M, Uccella N: Semiempirical molecular modeling into quercetin reactive site: Structural, conformational, and electronic features. J Agric Food Chem 2000, 48:3232-3237.

6. Payán-Gómez SA, Flores-Holguín N, Pérez-Hernández A, PinónMiramontes M, Glossman-Mitnik D: Computational molecular characterization of the flavonoid morin and its $\mathrm{Pt}(\mathrm{II}), \mathrm{Pd}(\mathrm{II})$ and $\mathrm{Zn}$ (II) complexes. J MolMod in press.

7. Lekka CE, Ren J, Meng S, Kaxiras E: Structural, electronic and optical properties of representative Cu-flavonoid complexes. J Phys Chem B 2009, 113:6478-6483.

8. Malesev D, Kuntic V: Investigation of metal-flavonoid chelates and the determination of flavonoids via metal-flavonoid complexing reactions. J Serb Chem Soc 2007, 72:921-939.

9. Zhao Y, Truhlar DG: Density functionals with broad applicability in chemistry. Acc Chem Res 2008, 41:157-167.
10. Parr RG, Yang W: Density Functional Theory of Atoms and Molecules New York: Oxford University Press; 1989.

11. Geerlings $P$, DeProft F, Langenaeker W: Conceptual density functional theory. Chem Rev 2003, 103:1793-1873.

12. Zandler ME, D'Souza F: The remarkable ability of B3LYP/3-21G(*) calculations to describe geometry, spectral and electrochemical properties of molecular and supramolecular porphyrin-fullerene conjugates. Comptes Rendus Chimie 2006, 9:960-981.

13. Lewars E: Computational Chemistry - Introduction to the Theory and Applications of Molecular and Quantum Mechanics Norwell, MA: Kluwer Academic Publishers; 2003.

14. Young D: Computational Chemistry: A Practical Guide for Applying Techniques to Real-World Problems New York: John Wiley \& Sons; 2001.

15. Jensen F: Introduction to Computational Chemistry Chichester: John Wiley \& Sons; 2007.

16. Cramer CJ: Essentials of Computational Chemistry - Theories and Models Chichester: John Wiley \& Sons; 2002

17. Tomasi J, Mennucci B, Cancès E: The IEF version of the PCM solvation method: An overview of a new method addressed to study molecular solutes at the QM ab initio level. J Mol Struct - THEOCHEM 1999, 464:211-226.

18. Frisch MJ, Trucks GW, Schlegel HB, Scuseria GE, Robb MA, Cheeseman JR, Montgomery JA Jr, Vreven T, Kudin KN, Burant JC, Millam JM, lyengar SS, Tomasi J, Barone V, Mennucci B, Cossi M, Scalmani G, Rega N, Petersson GA, Nakatsuji H, Hada M, Ehara M, Toyota K, Fukuda R, Hasegawa J, Ishida M, Nakajima T, Honda Y, Kitao O, Nakai H, Klene M, Li X, Knox JE, Hratchian HP, Cross JB, Bakken V, Adamo C, Jaramillo J, Gomperts R, Stratmann RE, Yazyev O, Austin AJ, Cammi R, Pomelli C, Ochterski JW, Ayala PY, Morokuma K, Voth GA, Salvador P, Dannenberg JJ, Zakrzewski VG, Dapprich S, Daniels AD, Strain MC, Farkas O, Malick DK, Rabuck AD Raghavachari K, Foresman JB, Ortiz JV, Cui Q, Baboul AG, Clifford S, Cioslowski J, Stefanov BB, Liu G, Liashenko A, Piskorz P, Komaromi I, Martin RL, Fox DJ, Keith T, Al-Laham MA, Peng CY, Nanayakkara A, Challacombe M, Gill PMW, Johnson B, Chen W, Wong MW, Gonzalez C, Pople JA: Gaussian 03, Revision E.01 Gaussian, Inc., Wallingford, CT; 2004.

19. Stratmann RE, Scuseria GE, Frisch MJ: An efficient implementation of time-dependent density-functional theory for the calculation of excitation energies of large molecules. J Chem Phys 1998, 109:8218-8224

20. Bauernschmitt $R$, Ahlrichs $R$ : Treatment of electronic excitations within the adiabatic approximation of time-dependent density functional theory. Chem Phys Lett 1996, 256:454-464.

21. Casida ME, Jamorski C, Casida KC, Salahub DR: Molecular excitation energies to high-lying bound states from time-dependent densityfunctional response theory: Characterization and correction of the time-dependent local density approximation ionization threshold. $J$ Chem Phys 1998, 108:4439-4449.

22. Gorelsky SI: Swizard program. [http://www.sg-chem.net/]

23. ChemCraft 1.6 [http://www.chemcraftprog.com]

24. Gorelsky SI: AOMix program. [http://www.sg-chem.net/].

25. Mendoza-Wilson AM, Glossman-Mitnik D: CHIH-DFT deternmination of the molecular structure, infrared and ultraviolet spectra of the flavonoid quercetin. J Mol Struct - THEOCHEM 2004, 681:71-76.

26. Mendoza-Wilson AM, Glossman-Mitnik D: CHIH-DFT study of the electronic properties and chemical reactiviy of quercetin. J Mol Struct THEOCHEM 2005, 716:67-72.

27. Fossen T, Andersen OM: Spectroscopic techniques applied to flavonoids. In Flavonoids - Chemistry, Biochemistry and Applications Volume 1. 1st edition. Edited by: Andersen OM, Markham KR, Boca Ratón. FL: Taylor and Francis, LLC; 2006:37-142.

28. Zevallos J, Toro-Labbé A: A theoretical analysis of the Kohn-Sham and Hartree-Fock orbitals and their use in the determination of electronic properties. J Chil Chem Soc 2003, 48:39-47.

doi: 10.1186/1752-153X-4-12

Cite this article as: Payán-Gómez et al., Computational molecular characterization of the flavonoid rutin Chemistry Central Journal 2010, 4:12 